Article

\title{
Power Factor Corrector with Bridgeless Flyback Converter for DC Loads Applications
}

\author{
Sheng-Yu Tseng *D, Po-Jui Huang and Dong-Heng Wu \\ Department of Electircal Engineering, Chang Gung University, Tao-Yuan 33302, Taiwan; \\ leon19941214@gmail.com (P.-J.H.); dondon8268@gmail.com (D.-H.W.) \\ * Correspondence: sytseng@mail.cgu.edu.tw; Tel.: +886-3-2118800 (ext. 5706)
}

Received: 30 August 2018; Accepted: 5 November 2018; Published: 9 November 2018

check for updates

\begin{abstract}
Since power systems with a DC distribution method has many advantages, such as conversion efficiency increase of about $5-10 \%$, cost reducing by about $15-20 \%$ and so on, the AC distribution power system will be replaced by a DC distribution one. This paper presents a DC load power system for a DC distribution application. The proposed power system includes two converters: DC/DC converter with battery source and power factor corrector (PFC) with a line source to increase the reliability of the power system when renewable energy or energy storage equipment are adopted. The proposed PFC adopts a bridgeless flyback converter to achieve power factor correction for supplying power to DC loads. When the bridgeless flyback converter is used to achieve PFC, it needs two transformers to process positive and negative half periods, respectively. In order to increase conversion efficiency, the flyback one can add two sets of the active clamp circuit to recover energies stored in leakage inductances of transformers in the converter. Therefore, the proposed bridgeless flyback converter can not only integrate two transformers into a single transformer, but also share a clamp capacitor to achieve energy recovery of leakage inductances and to operate switches with zero-voltage switching (ZVS) at the turn-on transition. With this approach, the proposed converter can increase conversion efficiency and decrease component counts, where it results in a higher conversion efficiency, lower cost, easier design and so on. Finally, a prototype with a universal input voltage source (AC 90-265 V) under output voltage of $48 \mathrm{~V}$ and maximum output power of $300 \mathrm{~W}$ has been implemented to verify the feasibility of the proposed bridgeless flyback converter. Furthermore, the proposed power system can be operated at different cases among load power $P_{L}$, output power $P_{D C 1}$ of DC/DC converter and output power $P_{D C 2}$ of the proposed PFC for supplying power to DC loads.
\end{abstract}

Keywords: bridgeless flyback converter; PFC; active clamp circuit; ZVS; DC distribution

\section{Introduction}

Since power systems with a DC distribution method has many advantages, such as conversion efficiency increase of about $5-10 \%$, cost reducing by about $15-20 \%$ and so on, the AC distribution power system will be replaced by a DC distribution one [1]. Figure 1 shows a block diagram of a power system for DC load applications. The power sources of the power system can adopt utility line, solar arrays, battery or wind turbine, etc. The power system using a power processor is widely applied to the general electrical or electronic equipment. In order to obtain a lighter weight and a smaller volume, a switching-mode converter is regarded as the power processor of the power system. When a power factor corrector (PFC) is used for the AC/DC power system [2-12] to protect the line source from harmonic current pollution, it has to meet the recommended limits of harmonics in supply current by various international power quality standards, such as the International Electrotechnical Commission (IEC) 61000-3-2 [2]. Therefore, the AC/DC converter adopts PFC techniques to increase 
power factor (PF), in which input voltage waveform can be made to be completely in phase with the input current one, implying approximately unity power factor.

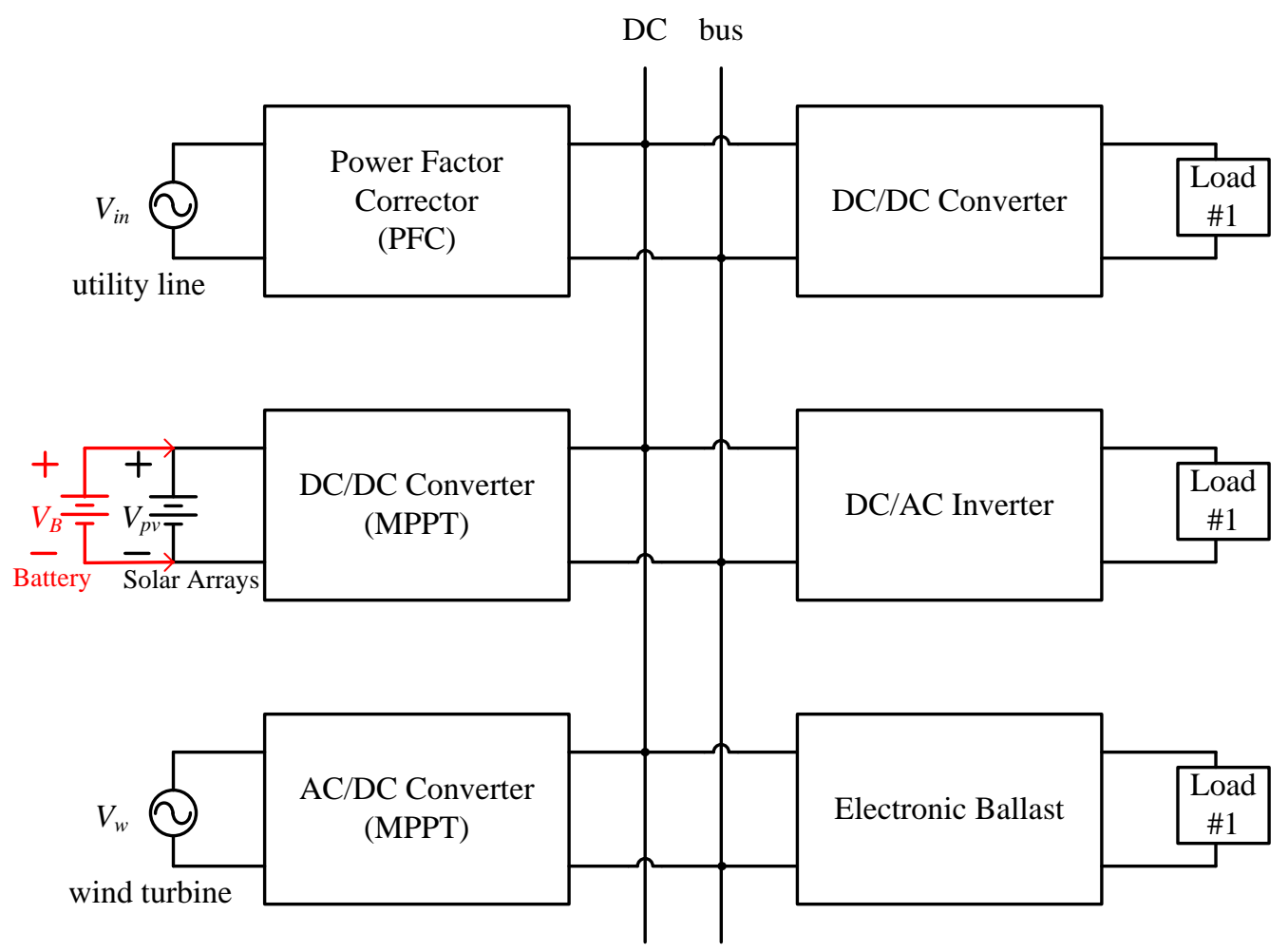

Figure 1. Block diagram of a power system for DC load applications.

In general, a boost converter, as shown in Figure 2, or buck-boost converter is adopted in the PFC system. In order to reduce the conduction losses of diodes, a bridgeless boost converter is adopted to achieve a higher power factor, as shown in Figure 3. Due to the universal input voltage source (AC 90-265 V), its output voltage is regulated at approximately $400 \mathrm{~V}$. For a power system under a lower level output voltage condition, it needs an extra DC/DC converter as a step-down converter. Therefore, the topology of two stages is used to achieve a lower output voltage, resulting in a higher cost and a lower conversion efficiency. Single stage topology with buck-boost converter has been an alternative solution in various power conversions. In order to further increase the step-down ratio, a bridgeless flyback converter is regarded as the power processor because of its topological advantages, such as simple circuit structure, low cost, and galvanic isolation, as depicted in Figure 4. It is adopted in not only low power isolated single-stage single-phase AC/DC converters which is regarded as the front end of the switching-mode power supply, but also uninterrupted power supplies (UPS), induction heating, electronic ballast, telecom power supplies, light emitting diode drivers [13-15], etc.

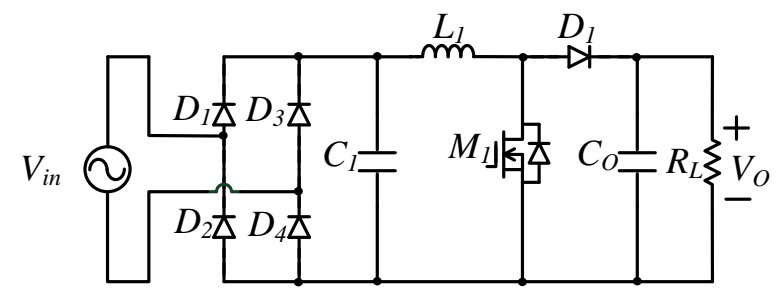

Figure 2. Schematic diagram of a boost converter for power factor corrector (PFC) applications. 


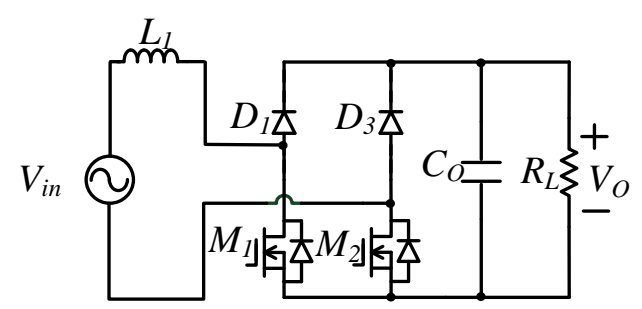

Figure 3. Schematic diagram of a boost converter using bridgeless topology for PFC applications.

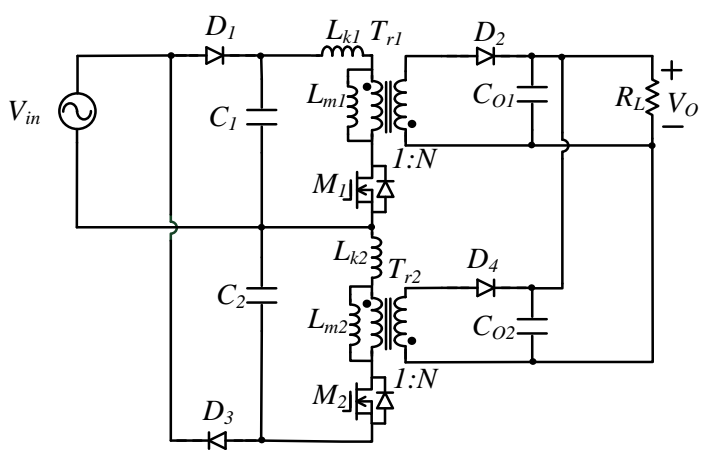

Figure 4. Schematic diagram of a bridgeless flyback for PFC applications.

Since a flyback converter adopts a transformer to be regarded as a stored inductor and an isolated transformer, a leakage inductance exists in the primary side, resulting in a higher voltage stress across switches of the converter when switches are turned off. In order to limit a high voltage stress across switches, a resistor-capacitor-diode (RCD) clamp circuit is used to reduce switch voltage spike. Although the RCD circuit can smooth out the voltage spike, the energy stored in leakage inductance is released to the clamp resistor. As a result, the conversion efficiency of the flyback converter does not increase. For improving conversion efficiency of the one with the RCD clamp circuit, an active clamp circuit is used to replace the RCD clamp circuit, as shown in Figure 5. With this approach, the energy stored in leakage inductance can be recycled and switches in the converter can be operated with zero-voltage switching (ZVS) at the turn-on transition [16,17].

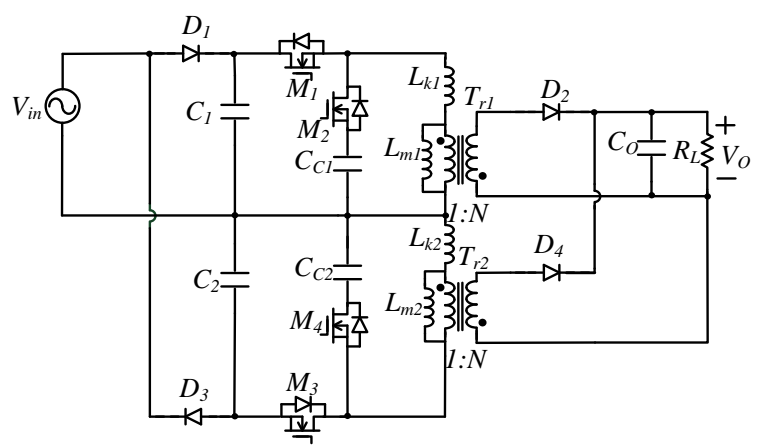

Figure 5. Schematic diagram of a bridgeless flyback converter with an active clamp circuit for PFC applications.

When the PFC adopts a bridgeless flyback converter, it needs to process power in a positive and negative half periods of the line source, resulting in that its component counts almost need twofold of its counterpart circuit $[18,19]$. Particularly, using more than one magnetic device in the bridgeless flyback converter impacts the advantage, which is the circuit simplicity. In order to further simplify the circuit structure, two transformers in the bridgeless flyback converter is replaced with a three-winding transformer, as illustrated in Figure 6. Furthermore, two active clamp circuits share a capacitor. It will reduce weight, volume and component counts, significantly. 


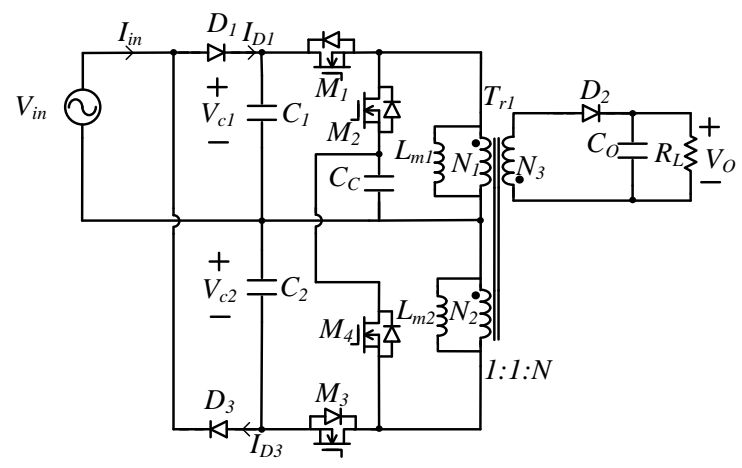

Figure 6. Schematic diagram of the proposed bridgeless flyback for PFC applications.

This paper proposes a bridgeless flyback converter, illustrating that the proposed one is without bridge diodes to remove the diode conduction loss and increase conversion efficiency. In addition, the proposed one adopts a three-winding transformer to substitute for two transformers. When the output maximum power of the proposed bridgeless flyback is the same as that of the conventional bridgeless flyback converter, as shown in Figure 5, its maximum input current $I_{i}$ is also the same as each other, and maximum working flux $B_{p k}$ of the transformer in the proposed converter is also the same as that in the conventional bridgeless flyback converter. Figure 7 shows a B-H curve of the transformer $T_{r}$ in the flyback converter. Since the conventional flyback converter uses a bridge rectifier to rectify input current $I_{i}$, the rectified input current $I_{i}$ can be obtained by a positive value during a complete switching cycle. Its B-H curve is illustrated in Figure 7a. As a result, the conventional flyback converter can use a set of transformers to implement PFC function. While, the bridgeless flyback converter, as shown in Figure 5, needs two sets of transformers to process energy under the positive half period and the negative half period. Its B-H curve is illustrated in Figure $7 \mathrm{~b}$. Due to the proposed bridgeless flyback converter with a three-winding transformer, its B-H curve is the same as the conventional flyback one, as shown in Figure 7a. Therefore, the proposed bridgeless converter can save a set of transformers. It can simplify the circuit structure, significantly. Therefore, the proposed bridgeless flyback converter for the PFC power system can achieve a higher power factor to avoid the line source from harmonic pollution, possesses soft-switching features in which switches are operated in ZVS at turn-on transition to increase conversion efficiency. It is suitable for a low power level application. This paper focuses on design and analysis of the proposed bridgeless flyback converter and power management for DC loads of power system.

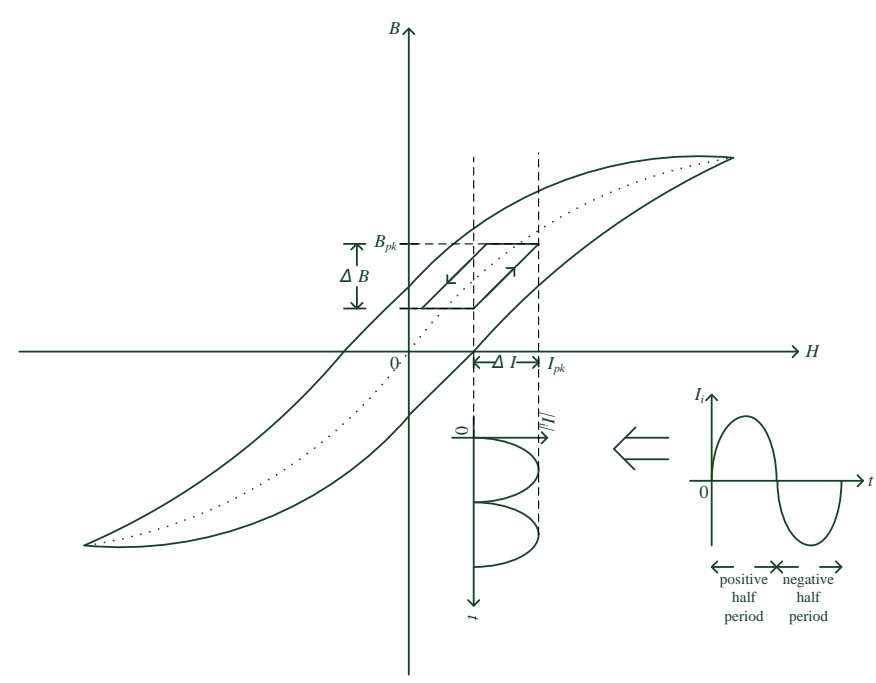

(a)

Figure 7. Cont. 


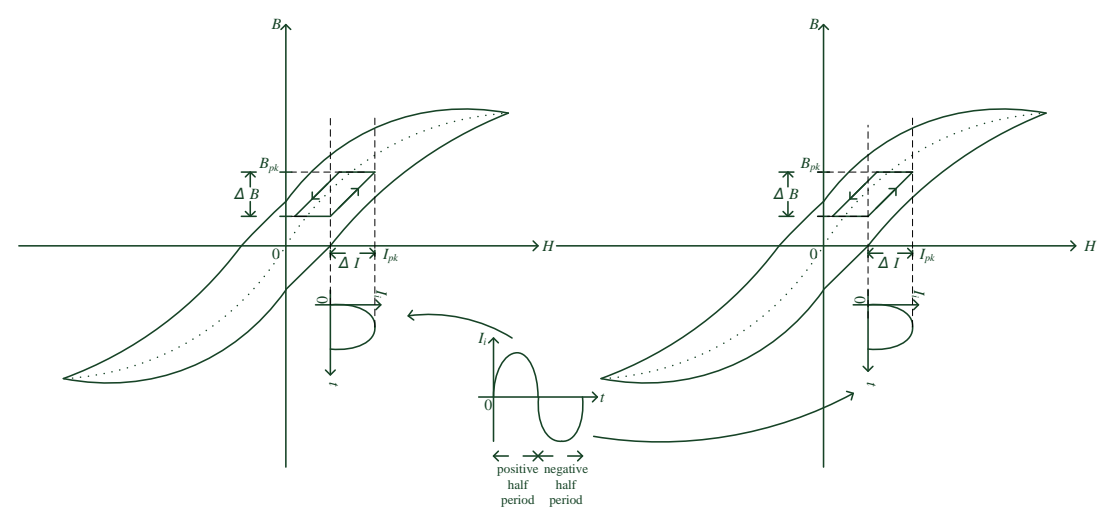

(b)

Figure 7. Plot of the B-H curve of transformer $T_{r}(\mathbf{a})$ in the conventional flyback converter, and (b) in the conventional bridgeless flyback converter for PFC applications.

\section{Control Algorithm of the Proposed System for DC Load Applications}

The proposed bridgeless PFC is applied to a DC load power system. In order to implement a DC load power system, the proposed one and a DC/DC converter with a battery source connected in parallel to supply power for DC loads. Its block diagram is shown in Figure 8. The control algorithm of the proposed power system for DC load applications is described in the following sections.

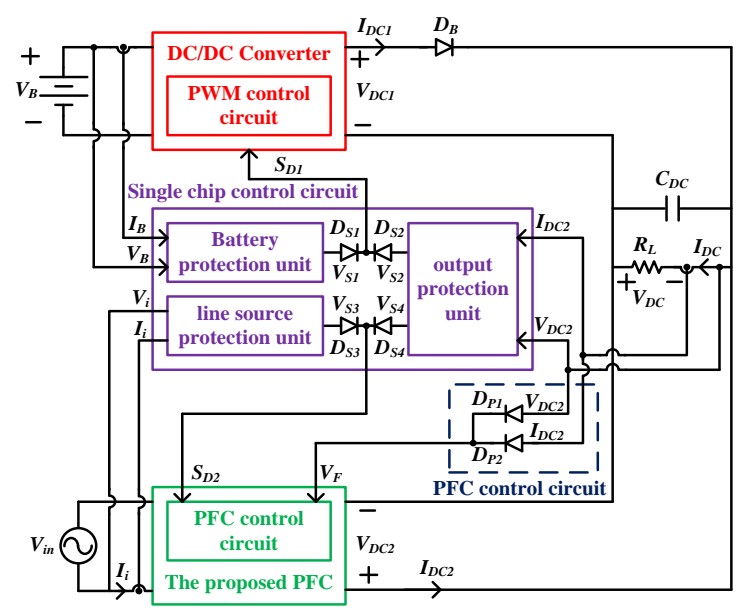

Figure 8. Block diagram of the proposed power system applications.

1. Circuit Topology of the Proposed Power System

The proposed DC load power system consists of a DC/DC converter with a battery source and a bridgeless PFC and single-chip control circuit. The output voltage $V_{D C 2}$ of the bridgeless PFC is close to and is greater than the output voltage $V_{D C 1}$ of the DC/DC converter. Therefore, the diode $D_{B}$ is used to block the voltage difference between voltages $V_{D C 2}$ and $V_{D C 1}$. The DC load $R_{L}$ is supplied power from the proposed PFC and the DC/DC converter. When the load power $P_{L}$ is less than or equal to $P_{D C 2(\max )}$ which is the maximum output power of the proposed PFC, the proposed PFC supplies power to load. If $P_{L}$ is greater than $P_{D C 2(\max )}$, the proposed PFC and the DC/DC converter supply power to load for achieving a DC load power system.

2. Control Algorithm of Each Unit

- DC/DC converter 
The DC/DC converter adopts a boost converter with a single-capacitor snubber [20]. It can transfer power from the battery to load. Since its output voltage $V_{D C 1}$ is less than the voltage $V_{D C 2}$, a diode $D_{B}$ is used to protect the DC/DC converter. Therefore, the protection diode with the output diode of boost converter is replaced by the extra diode $D_{B}$. If the operational state is in the $0<P_{L} \leq P_{D C 2 \text { (max) }}$ state, the battery with the DC/DC converter can be operated in the charging mode. It needs an extra charger to charge the battery. When the proposed power system is operated in an abnormal state, the single-chip control circuit sends a shutdown signal $S_{D 1}$ under a high level to the pulse width modulation (PWM) control circuit of the DC/DC converter. The DC/DC converter can be operated in the shutdown state to protect the DC/DC one.

- The Proposed PFC

The proposed PFC uses a bridgeless flyback converter which is regarded as a power factor corrector for increasing power factor between input voltage and input current of a line source. Its control circuit adopts a PWM IC for PFC control. Figure 9 illustrates conceptual waveforms of voltage $V_{C 1}$ and current $I_{D 1}$. Variation of current $I_{D 1}$ follows the sine waveform of input voltage $V_{C 1}$. Figure 9 a shows concept waveforms under a complete line period, while Figure $9 \mathrm{~b}$ depicts those waveforms under a positive half period. From Figure 9b, it can be seen that the proposed flyback converter can be operated in discontinuous conduction mode (DCM) or continuous conduction mode (CCM) under a positive half period. When the proposed one is operated in the A and C areas, inductor current $I_{L K}$ is in the DCM state due to a lower voltage level of input voltage $V_{C 1}$. If input voltage $V_{C 1}$ is during the $\mathrm{B}$ area interval, the proposed converter is operated in $\mathrm{CCM}$. According to the operational method of the proposed one as mentioned above, input voltage $V_{\text {in }}$ and current $I_{i}$ are in phase. Therefore, the proposed flyback converter can increase PF and reduce total harmonic distortion (THD).

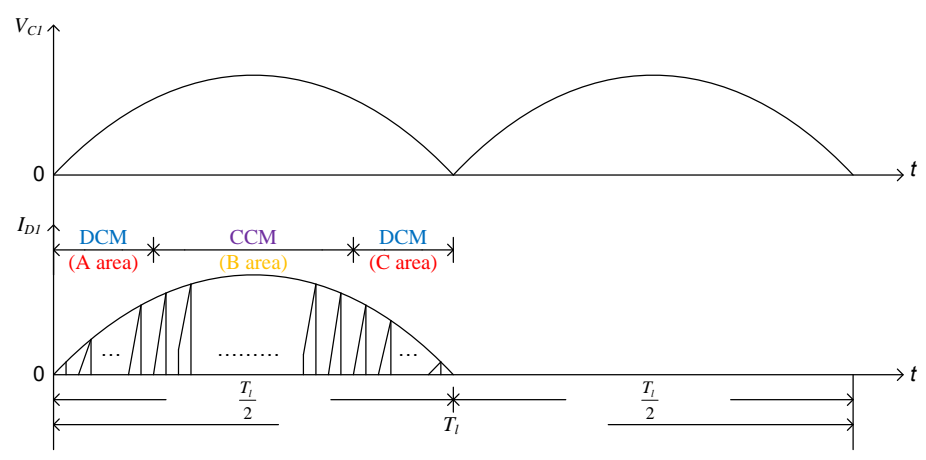

(a)

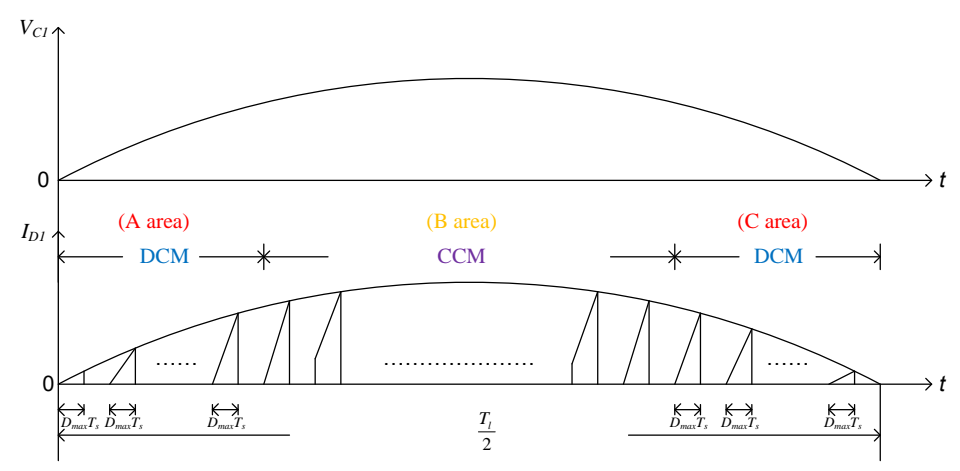

(b)

Figure 9. Conceptual waveforms of voltage $V_{C 1}$ and current $I_{D 1}$ : (a) Under a complete line period, and (b) under a positive half period. 
In Figure 8, when output current $I_{D C 2}$ of the proposed PFC is less than or is equal to the maximum output current $I_{D C 2(\max )}$, the output feedback voltage $V_{F}$ is equal $V_{D C 2}$ (diode $D_{P 1}$ is forward biased). The proposed PFC is operated as the voltage regulator. If $I_{D C 2}$ is greater than $I_{D C 2(\max )}$, the output current $I_{D C 2}$ is regulated at $I_{D C 2(\max )}$. That is, the proposed one is operated as the current regulator. The voltage $V_{F}$ is equal to $I_{D C 2(\max )}$ and the diode $D_{P 2}$ is in the forwardly bias state. In addition, when the proposed power system has an abnormal operational condition, the shutdown signal voltage $S_{D 2}$ is changed from a low level to a high level. The proposed PFC is shut down to protect the proposed one.

3. Single-Chip Control Circuit

The single-chip control circuit includes three units: The battery protection unit, line source protection unit and output protection unit. According to the operational relationships between DC/DC converter and the proposed PFC, the operational cases are divided into four cases, as listed in Table 1. Symbol definition of the proposed power system is listed in Table 2. Their operational conditions are described in the following section.

- Case I: $P_{L}=0 \mathrm{~W}$

When $P_{L}=0 \mathrm{~W}$, the DC/DC converter with battery source and the proposed PFC are operated in the shutdown mode.

- Case II: $0<P_{L} \leq P_{D C 2(\max )}$

When $0<P_{L} \leq P_{D C 2(\max )}, P_{B}=0 \mathrm{~W}$ and $P_{D C 2}=P_{L}$. The DC/DC converter with battery source and the proposed $\mathrm{PFC}$ with line source are operated in the working state.

- Case III: $P_{D C 2(\max )}<P_{L} \leq P_{D C 2(\max )}+P_{B(\max )}$

When $P_{D C 2(\max )}<P_{L} \leq P_{D C 2(\max )}+P_{B(\max )}, P_{D C 2}=P_{D C 2(\max )}$ and $P_{B}=P_{L}-P_{D C 2(\max )}$. The DC/DC converter and the proposed PFC are in the working state.

- Case IV: $P_{L}>P_{D C 2(\max )}+P_{B(\max )}$

When $P_{L}>P_{D C 2(\max )}+P_{B(\max )}$, the proposed power system is operated in the over-load state. Therefore, the DC/DC converter and the proposed PFC are in the shutdown state.

There are three protection units in the proposed power system: Battery protection, line source protection and output protection units. In order to increase protections of the proposed power system, hardware and software methods are adopted to protect the proposed one. Due to the same protection functions between hardware and software methods, the operation of hardware protection circuit is introduced in this paper. Figure 10 shows a block diagram of the single chip control circuit for the hardware protection circuit. In the battery protection unit, when $I_{B}>I_{B(\max )}$, the discharging current $I_{B}$ is in the over-current state. Voltage $V_{B 1}$ is changed from a low level to a high level. Voltage $S_{D 1}$ is equal to $V_{S 1}\left(=V_{B 1}\right)$. The DC/DC converter is shut down to protect the battery. If $V_{B}<V_{B(\text { min })}$, the battery is in the under-voltage state. Voltage single $V_{B 2}$ is changed from a low level to a high level, and signal $S_{D 1}$ is the same as $V_{S 1}\left(=V_{B 2}\right)$. Therefore, the DC/DC converter is also shut down.

In the line source protection unit, when $V_{i}<V_{i(\text { min })}(=\mathrm{AC} 90 \mathrm{~V})$, the proposed PFC is shut down by $S_{D 2}$. In this case, the line source is in the under-voltage state, and voltage signal $V_{i 1}$ varies from a low level to a high level. Since $V_{i 1}=V_{S 3}=S_{D 2}$, the proposed PFC is shut down by signal $S_{D 2}$, which is in a high level state. If $I_{i}>I_{i(\max )}$, the signal $V_{i 2}$ is equal to $V_{S 3}\left(=S_{D 2}\right)$, and $V_{i 2}$ is in a high level state. The proposed PFC is operated in the over-current state and it is shut down by $S_{D 2}$. In the output protection unit, there are two cases to protect the proposed power system. One is that output voltage is in the under-voltage state. The other one is that output current is in the over-current state. When two protection cases occur, the proposed power system is shut down. In the under voltage state, $V_{D C}<V_{D C \text { (min) }}$, voltage $V_{D 1}=V_{S 2}=S_{D 1}=V_{S 4}=S_{D 2}$ is changed from a low level to a high level to

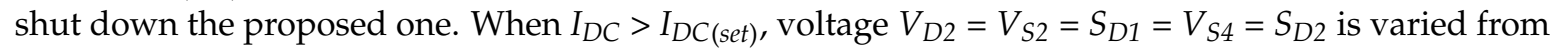
a low level to a high level. The proposed one is shut down. Therefore, the proposed power system 
can use the battery protection unit, line source protection unit and output protection unit to avoid the abnormal operational condition in the proposed power system.

Table 1. Operational conditions of the proposed power system for DC load applications.

\begin{tabular}{ccccc}
\hline \multirow{2}{*}{ Cases } & \multicolumn{2}{c}{ Power Distribution } & \multicolumn{2}{c}{ Operational Conditions } \\
\cline { 2 - 4 } & $\begin{array}{c}\text { DC/DC Converter with } \\
\text { Battery Source }\end{array}$ & The Proposed PFC & $\begin{array}{c}\text { DC/DC Converter } \\
\text { with Battery Source }\end{array}$ & The Proposed PFC \\
\hline$P_{L}=0 \mathrm{~W}$ & $P_{B}=0 \mathrm{~W}$ & $P_{D C 2}=0 \mathrm{~W}$ & shutdown & shutdown \\
$0<P_{L} \leq P_{D C 2(\max )}$ & $P_{B}=0 \mathrm{~W}$ & $P_{D C 2}=P_{L}$ & work & work \\
$P_{D C 2(\max )}<P_{L} \leq$ & $P_{B}=P_{L}-P_{D C 2(\max )}$ & $P_{D C 2}=P_{D C 2(\max )}$ & work & work \\
$P_{D C 2(\max )}+P_{B(\max )}$ & $P_{B}=0 \mathrm{~W}$ & $P_{D C 2}=0 \mathrm{~W}$ & shutdown & shutdown \\
$P_{L}>P_{D C 2(\max )}+$ & $P_{B(\max )}$ & & & \\
\hline
\end{tabular}

Table 2. Symbol definition of the proposed power system for DC load applications.

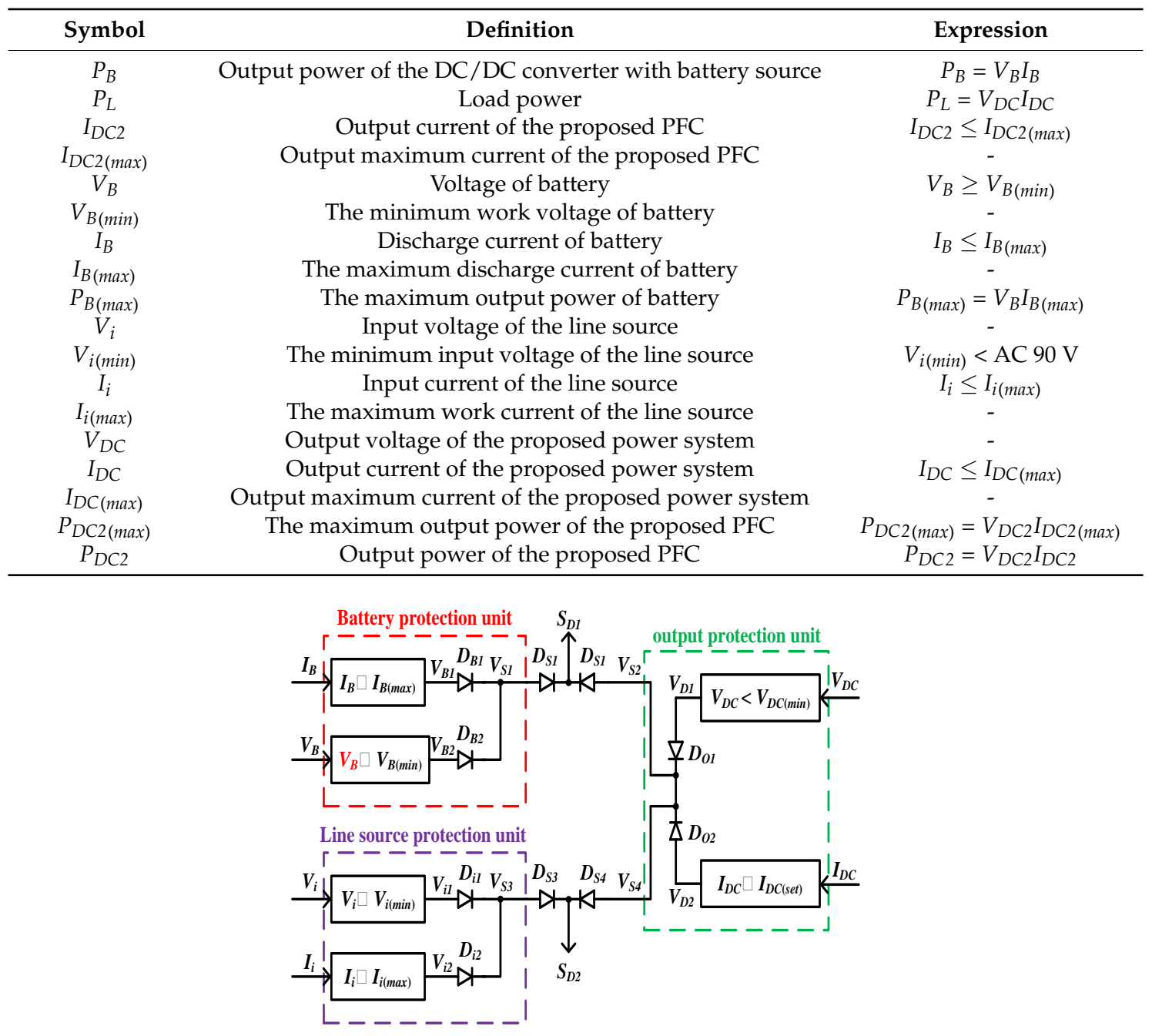

Figure 10. Block diagram of the single chip control circuit for DC Load circuit.

\section{Operational Principle of the Proposed PFC}

The proposed bridgeless flyback converter uses a three-winding transformer to achieve operations of the positive and negative half periods of the line source, as depicted in Figure 6. Its equivalent circuit is illustrated in Figure 11a,b, respectively. When the line source enters the positive half period, switches $M_{1}$ and $M_{2}$ are operated in complementary. During this time interval, switches $M_{3}$ and $M_{4}$ are always turned off, as shown in Figure 11a. The input energy supplied by the line source is 
transferred to load through windings $N_{1}$ and $N_{3}$ of the transformer. Furthermore, when the proposed converter is operated in the negative half period, switches $M_{1}$ and $M_{2}$ are turned off and switches $M_{3}$ and $M_{4}$, in turn, are operated in complementary, as depicted in Figure $11 \mathrm{~b}$.

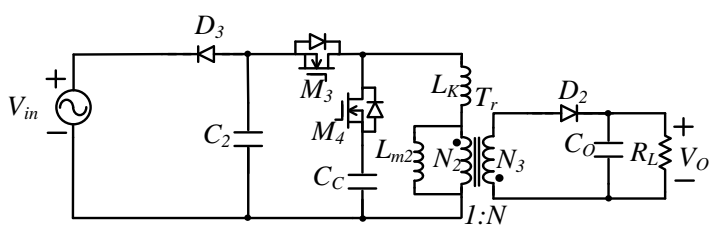

(a)

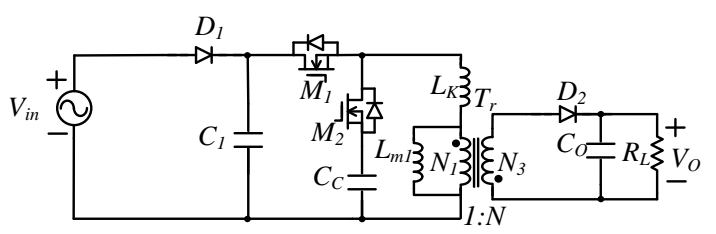

(b)

Figure 11. Schematic diagram of the proposed bridgeless flyback operated in (a) positive, and (b) negative half periods.

The operational principle of the proposed flyback converter is divided into two different half periods: Positive and negative half periods. According to operational principle of equivalent circuit shown in Figure 11a,b, operational modes of the proposed one operated in the positive period are similar to those modes in the negative period, except that switches $M_{1}$ and $M_{2}$ are changed to switches $M_{3}$ and $M_{4}$. Furthermore, since the period $T_{l}$ of the line source is much greater than $T_{s}$ of switching converter, the input voltage is regarded as a constant value during each switching period $T_{s}$. Therefore, the operational principle of the proposed bridgeless flyback converter can adopt, that input voltage is a constant DC voltage and the proposed one is operated in the positive half period of the line source, to explain its operational principle. According to the operational principle of the proposed converter, operational modes of the proposed one are divided into seven modes. Each operational mode is shown in Figure 12 over one switching cycle, and its key waveforms are illustrated in Figure 13. Its operational principle is described in the following.

- Mode 1 [Figure 12a; $t_{0} \leq t<t_{1}$ ]: Before $t_{0}$, switch $M_{1}$ is kept in the turn-on state, while $M_{2}$ is in the turn-off state. When $t=t_{0}$, current $I_{D S 1}$ of switch $M_{1}$ reaches to the initial current which is the minimum inductor current $I_{L}(0)$ of the proposed converter operated in continuous conduction mode $(C C M)$. Within this time interval, the inductor current $I_{L K}$ linearly increases and current $I_{D S 1}$ is equal to $I_{L K}$. Since the diode $D_{2}$ is reverse biased, the capacitor $C_{0}$ supplies the load with energy. In this interval, inductance $L_{m 1}$ is in the stored energy state.

- Mode 2 [Figure 12b; $t_{1} \leq t<t_{2}$ ]: At $t=t_{1}$, switch $M_{1}$ is turned off and $M_{2}$ is operated in the off state. The energies stored in leakage inductor $L_{k}$ and magnetizing inductor $L_{m 1}$ are transferred to capacitors $C_{M 1}$ and $C_{M 2}$. Voltage $V_{D S 1}$ across switch $M_{1}$ is charged from $0 \mathrm{~V}$ to $\left(V_{\text {in }}+V_{o} / N\right)$ and voltage $V_{D S 2}$ across switch $M_{2}$ is charged from $\left(V_{i n}+V_{o} / N\right)$ to $0 \mathrm{~V}$. Since the charge time is very small, capacitor $C_{M 1}$ is in an approximately linear charging state and $C_{M 2}$ is in an approximately linear discharging state. The output capacitor $C_{o}$ maintains output voltage $V_{o}$ at a desired value.

- Mode 3 [Figure 12c; $t_{2} \leq t<t_{3}$ ]: When $t=t_{2}$, switch voltage $V_{D S 1}$ is equal to $\left(V_{\text {in }}+V_{o} / N\right)$ and $V_{D S 2}$ equals to $0 \mathrm{~V}$. Diode $D_{2}$ and $D_{M 2}$ starts to forwardly bias. Voltage of secondary winding in transformer $T_{r}$ is clamped to output voltage $V_{o}$. Within this time interval, inductance $L_{k}$ and capacitor $C_{c}$ are in a resonant manner. Furthermore, magnetizing inductor $L_{m 1}$ releases the energy through transformer $T_{r}$ to load.

- Mode 4 [Figure 12d; $t_{3} \leq t<t_{4}$ ]: At $t_{3}$, switch $M_{2}$ is turned on and switch $M_{1}$ is kept in the off state. Since the body diode $D_{M 2}$ is forward biased before switch $M_{2}$ is turned on, switch $M_{2}$ is operated with ZVS at turn-on transition. Inductance $L_{k}$ and capacitor $C_{c}$ are kept in the resonant state. The energy stored in $L_{m 1}$ is transferred to load by means of transformer $T_{r}$.

- Mode 5 [Figure 12e; $t_{4} \leq t<t_{5}$ ]: When $t=t_{4}$, switch $M_{2}$ is turned off. A new resonant network is formed between inductance $L_{k}$ and capacitors $C_{M 1}$ and $C_{M 2}$. Capacitor $C_{M 1}$ is discharged and $C_{M 2}$ is charged through inductance $L_{k}$. As a sequence, switch voltage $V_{D S 2}$ changes from $0 \mathrm{~V}$ to 
$\left(V_{\text {in }}+V_{o} / N\right)$, while $V_{D S 1}$ varies from $\left(V_{\text {in }}+V_{o} / N\right)$ to $0 \mathrm{~V}$. Magnetizing inductance $L_{m 1}$ is in the released energy state. Diode $D_{2}$ maintains in the forwardly bias state.

- Mode 6 [Figure 12f; $t_{5} \leq t<t_{6}$ ]: At $t_{5}$, switch voltage $V_{D S 1}$ is equal to $0 \mathrm{~V}$. Inductance current $I_{L k}$ equals a negative value. Voltage across inductance $L_{k}$ is equal to $\left(V_{i n}+V_{o} / N\right)$. The operational states of magnetizing inductance $L_{m 1}$ and diode $D_{2}$ are the same as those states of mode 5 .

- Mode 7 [Figure 12g; $t_{6} \leq t<t_{7}$ ]: When $t=t_{6}$, switch $M_{1}$ is turned on. Since body diode $D_{M 1}$ is forward biased before $t=t_{6}$, switch $M_{1}$ is operated with ZVS at turn-on transition. Inductance current $I_{L k}$ varies from a negative value to the initial current which is the minimum current value of inductance $L_{m 1}$ when the proposed converter is operated in CCM. When $t=t_{7}$, current of magnetizing inductance $L_{m 1}$ reaches its minimum value again, a new switching cycle will start.

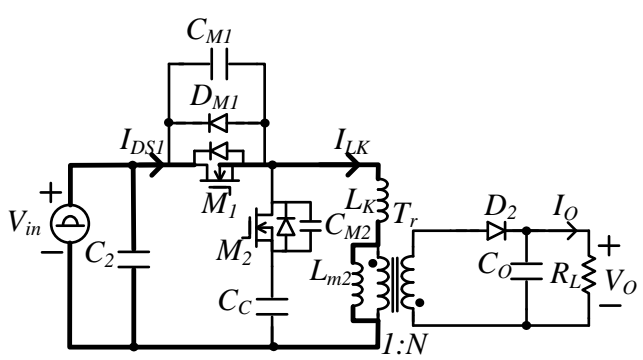

(a) Mode 1: $t_{0} \leq t<t_{1}$

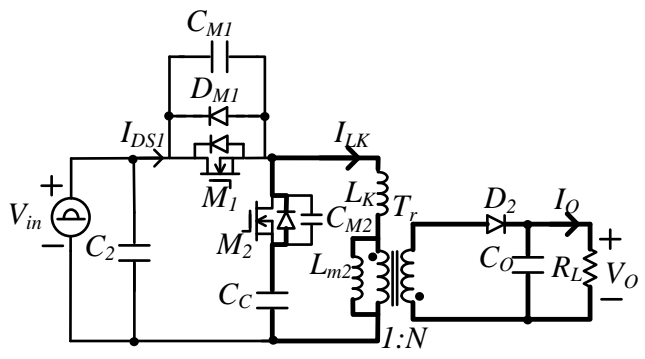

(c) Mode 3: $t_{2} \leq t<t_{3}$

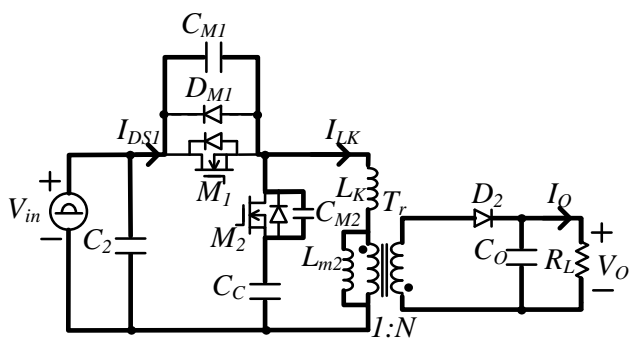

(e) Mode 5: $t_{4} \leq t<t_{5}$

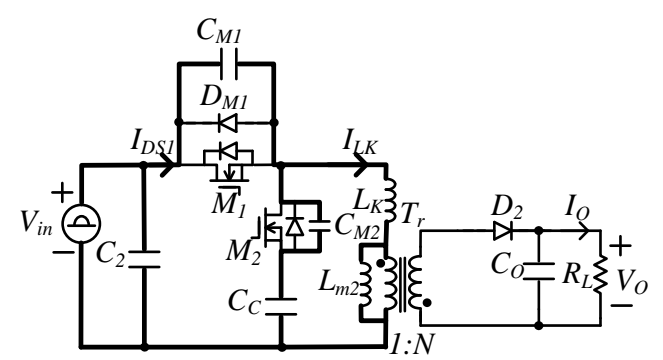

(b) Mode 2: $t_{1} \leq t<t_{2}$

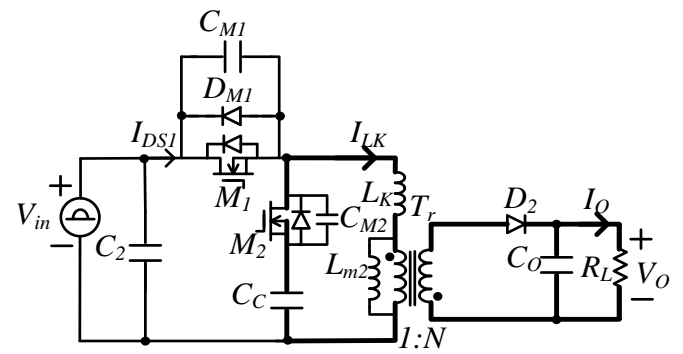

(d) Mode 4: $t_{3} \leq t<t_{4}$

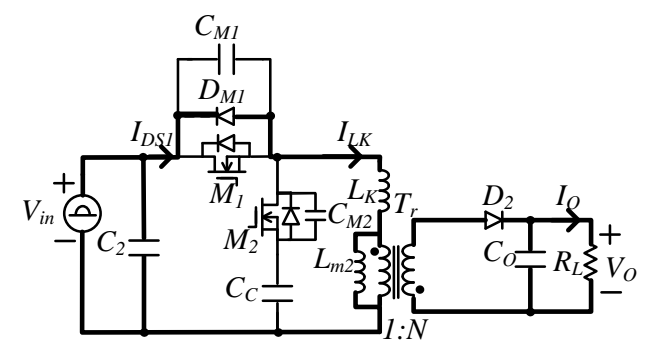

(f) Mode 6: $t_{5} \leq t<t_{6}$

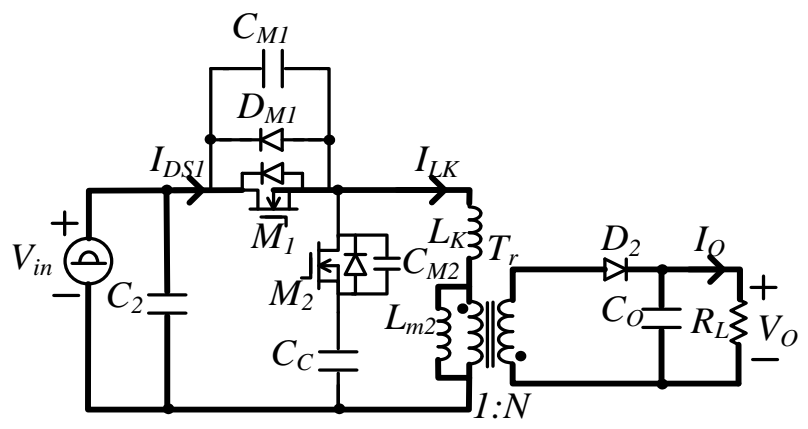

(g) Mode 7: $t_{6} \leq t<t_{7}$

Figure 12. Equivalent circuit of the proposed bridgeless flyback converter operated in CCM over one switching cycle during the positive half period of the input source. 


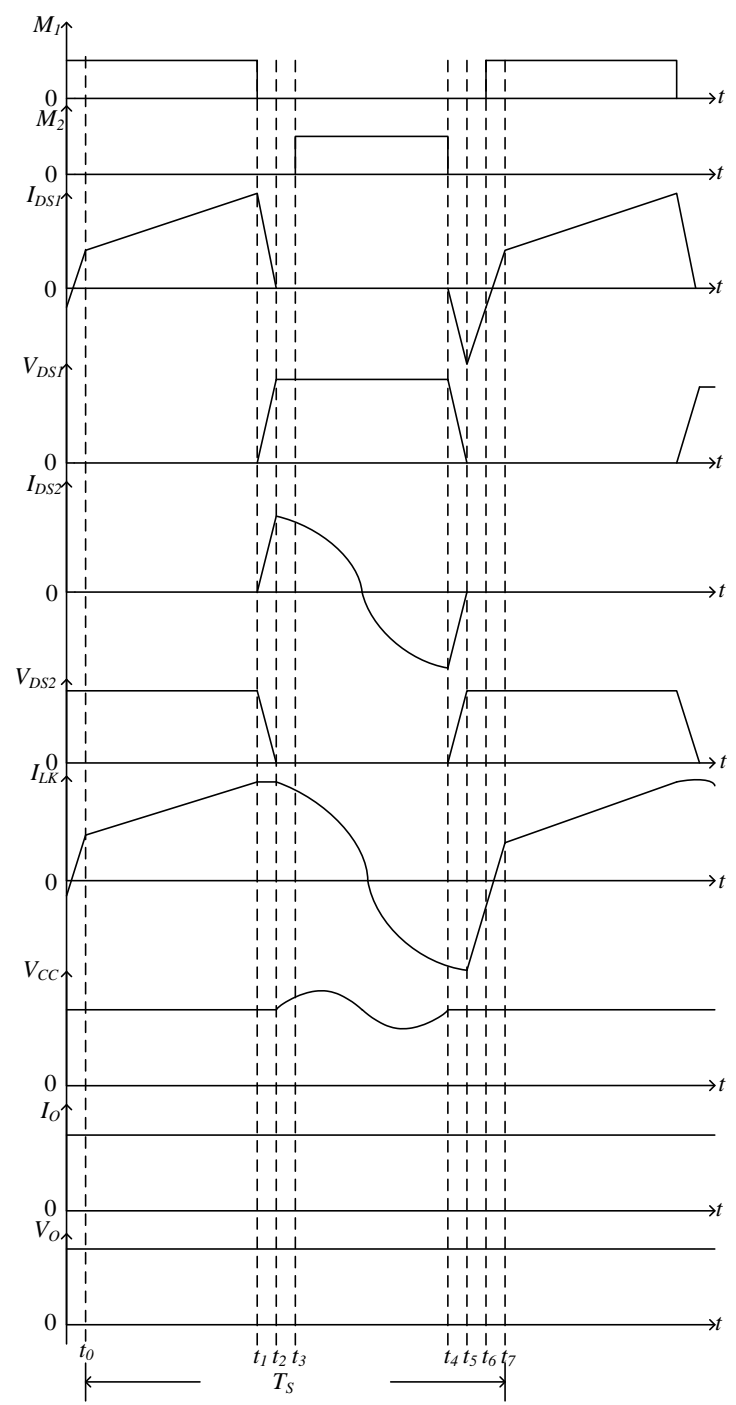

Figure 13. Key waveforms of the proposed converter operated in CCM under one switching cycle.

\section{Design of the Proposed PFC}

Due to the input voltage with a sine wave, the input current $I_{\text {in }}$ is time dependent. A function of peak current of switch $M_{1}$ or $M_{2}$ is, in turn, a function of duty cycle of the converter. Therefore, peak switch current $I_{D S 1}$ needs to be determined as a function of which the instantaneous operating point is on the input line period. Neglecting ripple current in the switch, switch current $I_{D S 1}(\phi)$ can be determined by

$$
I_{D S 1}(\phi)=\frac{I_{a v}(\phi)}{D(\phi)}
$$

where $I_{a v}(\phi)$ is the average input line current and $D(\phi)$ is an instantaneous duty cycle. In (1), one half of the line cycle period is considered to be normalized to the interval $[0, \pi]$, and $\phi$ is an arbitrary point on that interval. $I_{a v}(\phi)$ is given by

$$
I_{a v}(\phi)=\frac{\sqrt{2} P_{o}}{\eta V_{r m s}} \sin (\phi),
$$

where $P_{o}$ is the output power of the converter, $\eta$ indicates the conversion efficiency and $V_{r m s}$ is the input voltage of line source. The instantaneous duty cycle is

$$
D(\phi)=\frac{V_{o}}{V_{o}+\sqrt{2} N V_{r m s} \sin (\phi)}
$$


where $V_{o}$ is the output voltage and $N$ is the turns ratio of transformer $T_{r}$. As mentioned above, $D(\phi)$ can vary from $D_{\min }$ to 1 . In order to achieve systematic design of the proposed bridgeless flyback converter, its design is listed as follows:

- switches $M_{1}-M_{2}$

The turns ratio $N$ of transformer is selected to accommodate a low voltage ratio device for minimum duty cycle of switch to realize reasonable values, when the active clamp circuit in the proposed converter can provide a perfect suppression of the spike voltage across the main switch $M_{1}$ or $M_{3}$ due to leakage inductance of transformer, the maximum off-state voltage $V_{D S 1(\max )}$ can be determined by

$$
V_{D S 1(\max )}=\sqrt{2} V_{r m s}^{H L}+V_{O} / N,
$$

where $V_{r m s}^{H L}$ is the high line voltage of input source which is equal to AC $265 \mathrm{~V}$ and $V_{o}$ indicates the output voltage. The ranges of the minimum duty cycle can be given by

$$
D_{\min }^{L L}=\frac{V_{O}}{V_{O}+\sqrt{2} N V_{r m s}^{L L}}
$$

And

$$
D_{\min }^{H L}=\frac{V_{O}}{V_{O}+\sqrt{2} N V_{r m s}^{H L}}
$$

where $V_{r m s}^{L L}$ is the low line voltage of the input source which is equal to AC $90 \mathrm{~V}$. In general, the minimum duty cycle ranges are determined between 0.2 and 0.5 under the input source at high line or low line voltage.

The maximum switch average current $I_{D S 1(a v)}^{\max }$ occurs at the maximum load and the minimum line voltage, when power factor is approximately unity, the maximum switch average current $I_{D S 1(a v)}^{\max }$ is written by

$$
I_{D S 1(a v)}^{\max }=\frac{\sqrt{2} P_{O}^{F L}}{\eta V_{r m s}^{L L}}
$$

where $P_{O}^{F L}$ is output power of the proposed converter operated in the full load condition. Its worst case maximum peak current also occurs under the same operating conditions as above. The peak current $I_{D S 1(\text { peak })}^{\max }$ can be calculated from

$$
I_{D S 1(\text { peak })}^{\max }=\frac{\sqrt{2} P_{O}^{F L}}{\eta D_{\min }^{L L} V_{r m s}^{L L}}+\frac{\sqrt{2} V_{r m s}^{L L} D_{\min }^{L L} T_{S}}{2 L_{m}},
$$

where $L_{m}$ is the magnetizing inductance of transformer $T_{r}$ and $T_{S}$ is the switching period of switch $M_{1}$ or $M_{3}$. For this particular design, since voltage stress and peak current of active clamp switch $M_{2}$ or $M_{4}$ are the same as that of switch $M_{1}$ or $M_{3}$, device selection of switch $M_{2}$ or $M_{4}$ is the same as $M_{1}$ or $M_{3}$.

\section{- Transformer $T_{r}$}

Since input voltage changes from a low line voltage $V_{r m s}^{L L}$ to a high line voltage $V_{r m s}^{H L}$, it will affect the minimum duty cycle $D_{\min }^{L L}$ and $D_{\min }^{H L}$. In order to obtain a reasonable value of $D_{\min }^{L L}$ or $D_{\min }^{H L}$ for active clamp flyback converter, $D_{\min }^{L L}$ or $D_{\min }^{H L}$ is designed at between 0.3 and 0.5 . According to the reasonable ranges of $D_{\mathrm{min}}^{L L}$ or $D_{\mathrm{min}}^{H L}$ turns ratio $N$ is determined by

$$
N=\frac{\left(1-D_{\min }^{L L}\right) V_{O}}{\sqrt{2} D_{\min }^{L L} V_{r m s}^{L L}},
$$


Or

$$
N=\frac{\left(1-D_{\min }^{H L}\right) V_{O}}{\sqrt{2} D_{\min }^{H L} V_{r m s}^{H L}}
$$

The input voltage $V_{\text {in }}$ adopts a sine wave. During the positive half period or the negative half period, input voltage $V_{\text {in }}$ can vary from $0 \mathrm{~V}$ to the maximum value, and then from the maximum value to $0 \mathrm{~V}$. In order to determine magnetizing inductance $L_{m 1}\left(=L_{m}\right)$ or $L_{m 2}\left(=L_{m}\right)$, current variation value $\triangle I_{L m}$ of magnetizing inductance $L_{m 1}$ or $L_{m 2}$ is determined with the worst case maximum peak switch current as a reference value. Therefore, $\triangle I_{L m}$ can be written by

$$
\Delta I_{L m}=K I_{D S 1(\text { peak })}^{\max }=K\left(\frac{\sqrt{2} P_{O}^{F L}}{\eta D_{\min }^{L L} V_{r m s}^{L L}}+\frac{\sqrt{2} D_{\min }^{L L} V_{r m s}^{L L} T_{S}}{2 L_{m}}\right) .
$$

For this particular design, $\mathrm{K}$ is determined at approximately 0.1 .

\section{- Clamp Capacitor $C_{C}$}

Since switches $M_{1}-M_{4}$ are operated with ZVS at turn-on transition and the energy stored in leakage inductance $L_{K}$ can be recycled, it is by means of leakage inductance $L_{K}$ and clamp capacitor $C_{C}$ operated in the resonant manner. A better design of the proposed converter is to select the clamp capacitor $C_{C}$ value so that one half of the resonant period formed by the clamp capacitor $C_{C}$ and leakage inductance $L_{K}$ exceeds the maximum off time of switch $M_{1}$ or $M_{3}$. Therefore, clamp capacitor $C_{C}$ can be determined by

$$
C_{C} \approx \frac{\left(1-D_{\min }^{L L}\right)^{2} T_{S}^{2}}{\pi^{2} L_{K}}
$$

where $L_{K}$ is equal to $1 \sim 5 \%$ of magnetizing inductance $L_{m 1}$ or $L_{m 2}$.

- Output Capacitor $C_{o}$

The output capacitor $C_{o}$ is used to reduce output voltage ripple. Since the input voltage $V_{\text {in }}$ of the proposed converter is a half-wave rectification waveform, output voltage $V_{o}$ contains a voltage ripple with $120 \mathrm{~Hz}$. When the maximum peak output voltage $\triangle V_{o}$ is specified, output capacitor $C_{o}$ can be given by

$$
C_{o}=K \frac{P_{o}^{\max }}{240 \pi V_{o} \Delta V_{O}},
$$

where $P_{o}^{\max }\left(=P_{0}^{F L}\right)$ is the maximum output power. Furthermore, the required ripple current rating $I_{\mathrm{CO}(\mathrm{rms})}^{\max }$ for output capacitor is determined by

$$
I_{C O(r m s)}^{\max }=\frac{P_{o}^{\max }}{\sqrt{2} V_{O}} .
$$

\section{Measured Results}

In order to verify performances of the proposed power system, as shown in Figure 8, a prototype with following specifications was implemented. The proposed power system includes two converters: The DC/DC converter with battery source and the proposed PFC with line source. Their specifications are respectively shown in the following:

- The DC/DC converter with battery source

Input Voltage $V_{B}$ : DC 20-26 V (two batteries connected in series),

Switching frequency $f_{s}: 50 \mathrm{kHz}$,

Output Voltage $V_{D C 1}$ : DC $48 \mathrm{~V}$,

Maximum output current $I_{D C 1(\max )}: 2.5 \mathrm{~A}$, and 
Maximum output power $P_{D C 1(\max )}: 120 \mathrm{~W}$,

- $\quad$ The proposed PFC with line source

Input voltage $V_{\text {in }}$ : AC 90-265 V,

Switching frequency $f_{s}: 50 \mathrm{kHz}$,

Output Voltage $V_{D C 2}$ : DC $50 \mathrm{~V}$,

Maximum output current $I_{D C 2(\max )}: 6 \mathrm{~A}$,

Maximum output power $P_{D C 2(\max )}: 300 \mathrm{~W}$,

According to the previous specifications, the design values of the key components of the proposed power system can be determined. The DC/DC converter with battery source is shown in Figure 14 and the proposed PFC with line source is shown in Figure 6. According to design of the proposed flyback converter, parameter values in the proposed one is listed in Table 3. Semiconductor selection of the proposed one is illustrated in Table 4 . Their devices are determined as follows:

- The DC/DC converter with battery source

Switches $M_{1}, M_{2}$ : IRFP250,

Diodes $D_{1}, D_{2}$ : SR10100,

Inductances $L_{1}, L_{2}: 230 \mu \mathrm{H}$, and

Capacitor $C_{D C 1}: 1000 \mu \mathrm{F}$,

- The proposed PFC with line source

Switches $M_{1}-M_{4}$ : IRG4PH50KDPbF,

Transformer $T_{r}$ core: EE-55,

Diode $D_{2}$ : 40EPF06PbF,

Output capacitor $C_{O}: 2200 \mu \mathrm{F} / 63 \mathrm{~V}$

Diodes $D_{1}, D_{3}$ : HFA08TB60,

Capacitors $C_{1}, C_{2}: 0.1 \mu \mathrm{F} / 630 \mathrm{~V}$,

Clamp capacitor $C_{C}: 0.47 \mu \mathrm{F}$,

Turns ratio $\mathrm{N}$ of transformer $T_{r}: 0.5$,

$D^{L L}{ }_{\text {min }}: 0.43$, and

Magnetizing inductances $L_{m 1}, L_{m 2}: 2.72 \mathrm{mH}$,

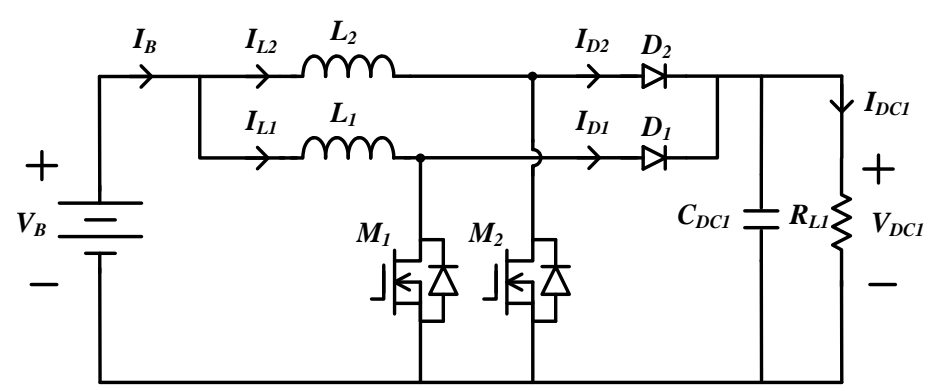

Figure 14. Schematic diagram of the DC/DC converter with battery source. 
Table 3. Parameter values of the proposed flyback converter.

\begin{tabular}{|c|c|c|c|c|}
\hline Parameter & Design Value & $\begin{array}{l}\text { Experimental } \\
\text { Value }\end{array}$ & $\begin{array}{l}\text { Design Value by } \\
\text { Equation }\end{array}$ & Conditions \\
\hline$I_{a v}(\Phi)$ & $5.55 \sin (\Phi) \mathrm{A}$ & - & $(2)$ & $\eta=85 \%, V_{r m s}=90 \mathrm{~V}, P_{O}=300 \mathrm{~W}$ \\
\hline$D_{\min }^{L L}$ & 0.43 & - & (5) & $V_{O}=48 \mathrm{~V}, V_{r m s}^{L L}=90 \mathrm{~V}, N=0.5$ \\
\hline$D_{\min }^{H L}$ & 0.204 & - & (6) & $V_{O}=48 \mathrm{~V}, V_{r m s}^{H L}=265 \mathrm{~V}, N=0.5$ \\
\hline$I_{D S 1(a v)}^{\max }$ & $5.5 \mathrm{~A}$ & - & (7) & $\eta=85 \%, V_{r m s}^{L L}=90 \mathrm{~V}, P_{O}^{\mathrm{FL}}=300 \mathrm{~W}$ \\
\hline$I_{D S 1(p e a k)}^{\max }$ & $13.1 \mathrm{~A}$ & - & (8) & $\begin{array}{c}\eta=85 \%, V_{r m s}^{L L}=90 \mathrm{~V}, P_{O}^{F L}=300 \mathrm{~W}, L_{m}=2.72 \\
\mathrm{mH}, D_{\min }^{L L}=0.43, T_{S}=20 \mu \mathrm{s}\end{array}$ \\
\hline$C_{C}$ & $0.41 \mu \mathrm{F}$ & $0.47 \mu \mathrm{F}$ & (12) & $L_{K}=32 \mu \mathrm{H}, D_{\min }^{L L}=0.43, T_{S}=20 \mu \mathrm{s}$ \\
\hline$C_{O}$ & $1730 \mu \mathrm{F}$ & $2200 \mu \mathrm{F}$ & (13) & $K=0.1, V_{O}=48 \mathrm{~V}, \Delta V_{O}=0.48 \mathrm{~V}, P_{O}^{\max }=300 \mathrm{~W}$ \\
\hline
\end{tabular}

Table 4. Semiconductor selection of the proposed flyback converter.

\begin{tabular}{ccc}
\hline Component & Design Maximum Voltage/Current Ratings & $\begin{array}{c}\text { Component Selection and Voltage/Average } \\
\text { Current/Peak Current }\end{array}$ \\
\hline$M_{1}-M_{4}$ & $470 \mathrm{~V} / 13.1 \mathrm{~A}$ & $\mathrm{IRG} 4 \mathrm{PH} 50 \mathrm{KDPbF}$ \\
& & $1200 \mathrm{~V} / 24 \mathrm{~A} / 90 \mathrm{~A}$ \\
$D_{1}-D_{3}$ & $375 \mathrm{~V} / 13.1 \mathrm{~A}$ & $\mathrm{HFA} 08 \mathrm{~TB} 60$ \\
$D_{2}$ & $235 \mathrm{~V} / 19.87 \mathrm{~A}$ & $600 \mathrm{~V} / 8 \mathrm{~A} / 60 \mathrm{~A}$ \\
& $40 \mathrm{EPF} 06 \mathrm{PbF}$ \\
\end{tabular}

Since this paper focuses on design and implementation of the bridgeless flyback converter, measured results of the DC/DC converter with battery source have only shown that output voltage $V_{D C 1}$ and current $I_{D C 1}$ under step-load changes and under supplying power to load in parallel connection. Measured output voltage $V_{D C 1}$ and current $I_{D C 1}$ waveforms under step-load changes between $10 \%$ and $100 \%$ of full load condition with duty ratio of $50 \%$ and repetitive period of $1 \mathrm{~s}$ is shown in Figure 15. From Figure 15, it can be seen that the voltage regulation of output voltage $V_{D C 1}$ has been limited within $\pm 1 \%$.

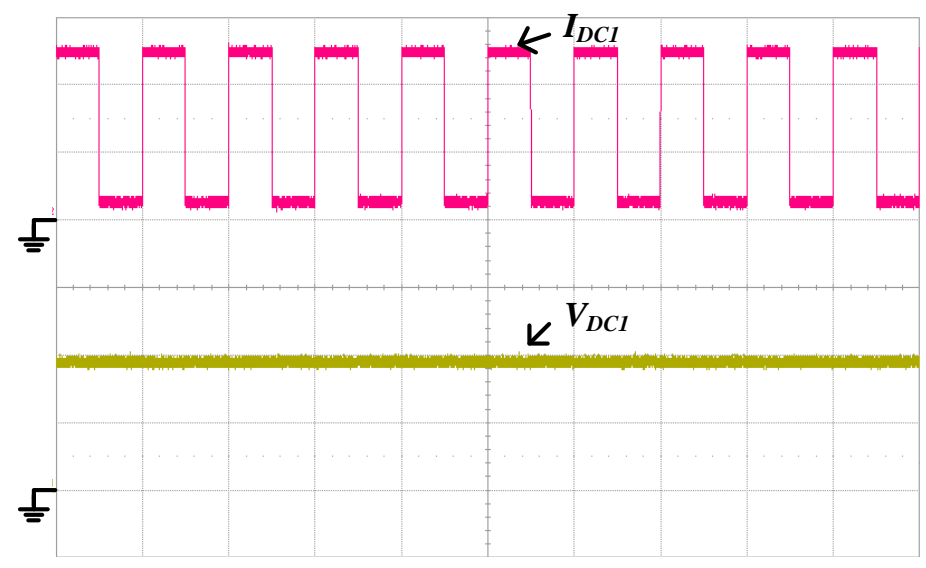

(VDC1: $25 \mathrm{~V} /$ div; IDC1: $1 \mathrm{~A} / \mathrm{div}$; time: $500 \mathrm{~ms} / \mathrm{div}$ )

Figure 15. Measured output voltage $V_{D C 1}$ and current $I_{D C 1}$ waveforms of step-load changes between $10 \%$ and $100 \%$ of full load condition with duty ratio of $50 \%$ and repetitive period of $1 \mathrm{~s}$.

For the proposed $\mathrm{PFC}$, since the input voltage $V_{\text {in }}$ of $\mathrm{AC} 90 \mathrm{~V}$ is the worst case for operational states of the proposed one, the experimental results are shown with the input voltage of AC $90 \mathrm{~V}$. Measured waveforms of input voltage $V_{i n}$ and current $I_{i}$ is shown in Figure 16 under the line source of AC 90 V. Figure 16a shows those waveforms under 10\% of full load condition and Figure 16b illustrates those waveforms under $100 \%$ of full load condition. From Figure 16, it can be found that input voltage $V_{\text {in }}$ and current $I_{i}$ are approximately in phase. Figure 17a illustrates measured waveforms of voltages 
$V_{C 1}, V_{C 2}$ and currents $I_{D 1}, I_{D 3}$ under $50 \%$ of full load condition and the input voltage of $90 \mathrm{~V}$, while Figure 17b shows measured waveforms of voltage $V_{C 1}$ and current $I_{D 1}$. From Figure 17, it can be seen that waveforms of currents $I_{D 1}$ and $I_{D 3}$ follow ones of voltages $V_{C 1}$ and $V_{C 2}$ variation, respectively. Since duty ratio $D$ varies from 0.204 to 1 , and the proposed flyback converter is operated in DCM or CCM. Figures 18 and 19 show measured waveforms of switch voltage $V_{D S}$ and current $I_{D S}$ under input voltage of $90 \mathrm{~V}$. Figure 18 illustrates measured waveforms of switch voltage $V_{D S 1}$ and current $I_{D S 1}$, and switch voltage $V_{D S 2}$ and current $I_{D S 2}$ and current $I_{D S 2}$ under $10 \%$ of full load condition and the input voltage of 90 V. From Figure 18, it can be found that the proposed flyback converter is operated in DCM. The active clamp capacitor can reduce the voltage spike and recover energy stored in leakage inductor of the transformer. Figure 19 depicts those waveforms under $30 \%$ of full load condition and the input voltage of $90 \mathrm{~V}$, from which it can be seen that switches $M_{1}$ and $M_{2}$ are operated in ZVS at turn-on transition. In Figures 18 and 19, voltage $V_{D S 1}$ across switch $M_{1}$ has a ring voltage. The ring voltage is generated by leakage inductor of secondary winding of transformer and parasitic capacitor of diode $D_{2}$ when switch $M_{1}$ is turned on. It can be eliminated by snubber circuit applied to diode $D_{2}$.

Measured output voltage $V_{D C 2}$ and current $I_{D C 2}$ waveforms under step-load changes between $10 \%$ and $100 \%$ of full load condition with duty ratio of $50 \%$ and repetitive period of $1 \mathrm{~s}$ as shown in Figure 20, from which it can be observed that the voltage regulation of output voltage $V_{D C 2}$ has been limited within $\pm 1 \%$. Figure 21 depicts the measured efficiency of the proposed PFC from light load to heavy load under AC $90 \mathrm{~V}$. When load is greater than $40 \%$ of full load condition, each efficiency is greater than $86 \%$. For further increase in conversion efficiency of the proposed converter, switches $M_{1}-M_{4}$ can adopt a lower conduction resistance to reduce conduction loss. It also decreases the switching frequency of the switch to reduce switching loss. In order to verify a high PF, the plot of power factor of the proposed one from light load to heavy load illustrated in Figure 22, from which it can be found that power factor of the proposed one can be greater than 0.8 under different input voltages. In particular, when input voltage is at a high line level and load is in the light load, PF has a lower value. Due to a lower output current $I_{D C 2}$, PFC control IC is difficult to control input current $I_{i}$, resulting in a lower PF. Figure 23 shows the harmonic current from light load to heavy load under different input voltage levels, illustrating that their harmonic current can meet requirements of IEC6100-3-2 class A.

According to operational cases of the proposed power system, there are four operational cases for DC load power variations. Figure 24 shows measured waveforms of voltages $V_{D C 1}$ and $V_{D C 2}$, and currents $I_{D C 1}$ and $I_{D C 2}$ from $P_{L}=0 \mathrm{~W}$ to $P_{L}=125 \mathrm{~W}$. Due to $P_{D C 2(\max )}=300 \mathrm{~W}$, operational case changes of the proposed one can be varied from case I to case II. When load power $P_{L}$ is from $0 \mathrm{~W}$ to $325 \mathrm{~W}$, operational case changes are from case I to case III. Those waveforms are shown in Figure 25. If $P_{L}$ variations are from $0 \mathrm{~W}$ to $450 \mathrm{~W}$, operational case charges are from case I to case IV. Those waveforms are shown in Figure 26. As mentioned above, the proposed power system can change operational case by the control algorithm of the proposed power system.

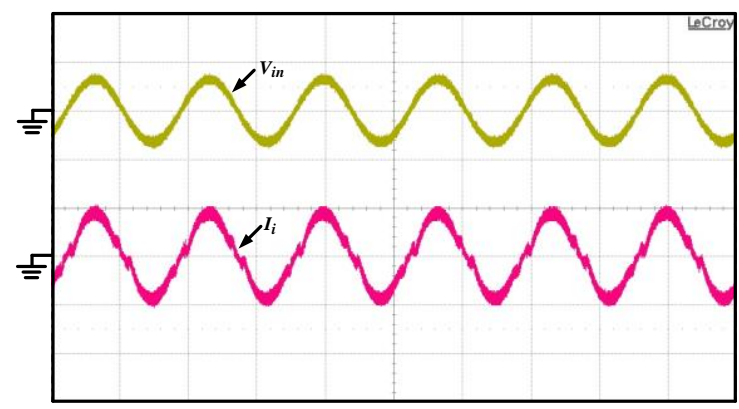

(Vin: $200 \mathrm{~V} /$ div; $I_{i:} 0.5 \mathrm{~A} / \mathrm{div}$; time: $10 \mathrm{~ms} / \mathrm{div}$ )

(a)

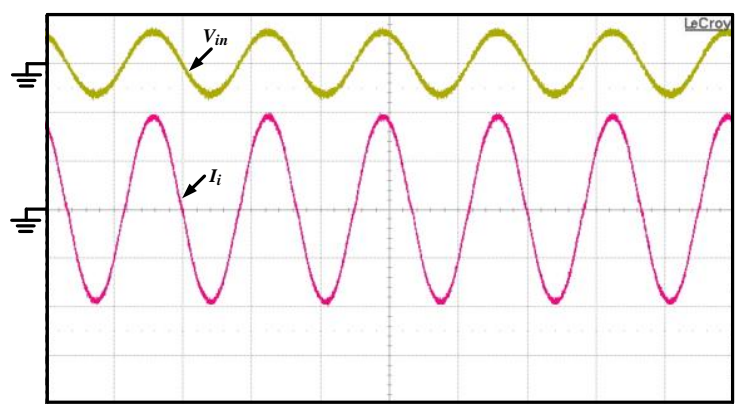

(Vin: $200 \mathrm{~V} /$ div; $I_{i:}: 2.5 \mathrm{~A} /$ div; time: $10 \mathrm{~ms} /$ div)

(b)

Figure 16. Measured waveforms of input voltage $V_{\text {in }}$ and input current $I_{i}$ under the line source of AC $90 \mathrm{~V}$ : (a) $10 \%$ of full load condition, and (b) $100 \%$ of full load condition. 


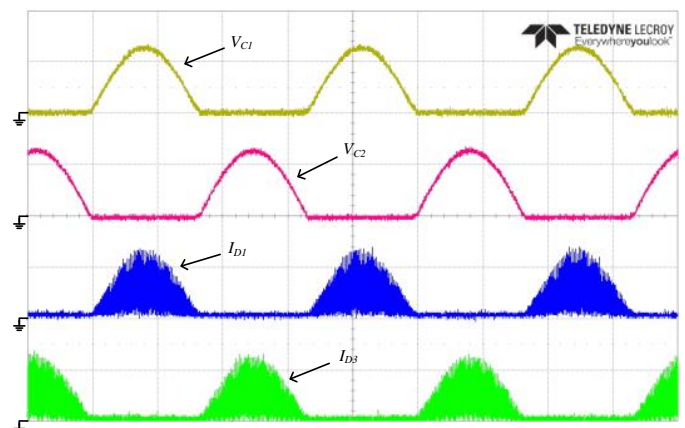

$\left(V_{C 1}, V_{C 2}: 100 \mathrm{~V} /\right.$ div; ID1, ID3: $\left.2 \mathrm{~A} / \mathrm{div} ; 5 \mathrm{~ms} / \mathrm{div}\right)$

(a)

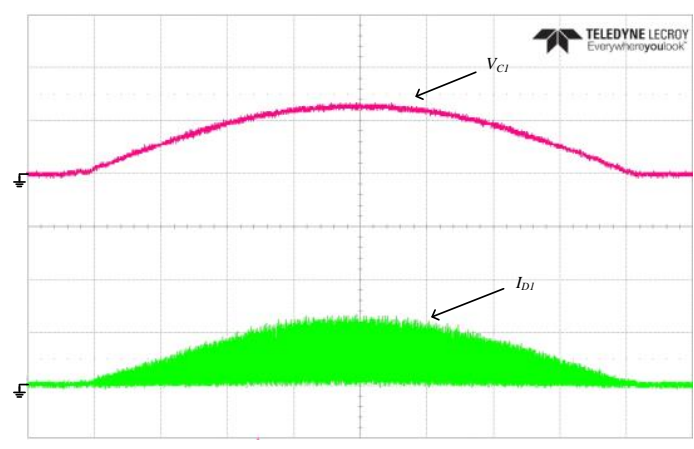

(VC1: $100 \mathrm{~V} /$ div; ID1: $2 \mathrm{~A} /$ div; $5 \mathrm{~ms} /$ div)

(b)

Figure 17. Measured waveforms of (a) voltages $V_{C 1}, V_{C 2}$ and currents $I_{D 1}, I_{D 3}$, and (b) voltage $V_{C 1}$ and current $I_{D 1}$ under $50 \%$ of full load condition and the input voltage of $90 \mathrm{~V}$.

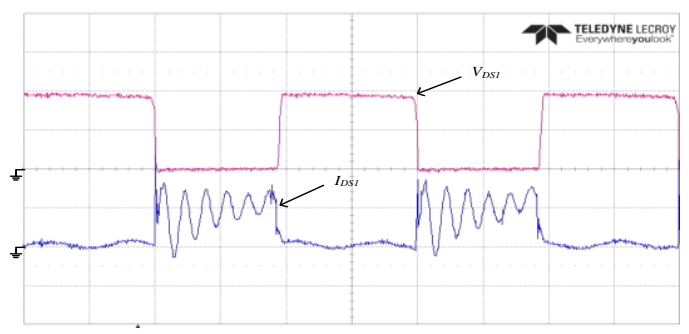

(VDC1: $100 \mathrm{~V} /$ div; IDS1: $0.5 \mathrm{~A} /$ div; $5 \mu \mathrm{s} / \mathrm{div})$

(a)

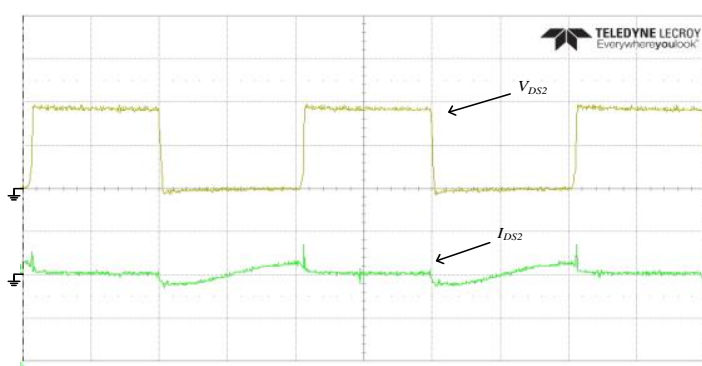

(VDC2: $100 \mathrm{~V} /$ div; IDS2: $0.5 \mathrm{~A} /$ div; $5 \mu \mathrm{s} /$ div)

(b)

Figure 18. Measured waveforms of (a) switch voltage $V_{D S 1}$ and current $I_{D S 1}$, and (b) switch voltage $V_{D S 2}$ and current $I_{D S 2}$ and current $I_{D S 2}$ under $10 \%$ of full load condition and the input voltage of $90 \mathrm{~V}$.

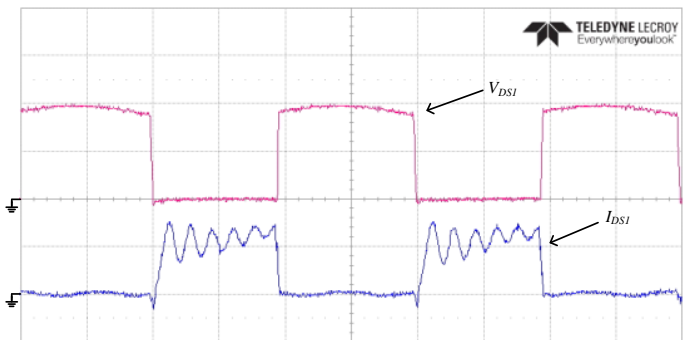

(VDC1: $100 \mathrm{~V} /$ div; IDS1: $1 \mathrm{~A} / \mathrm{div} ; 5 \mu \mathrm{s} / \mathrm{div})$

(a)

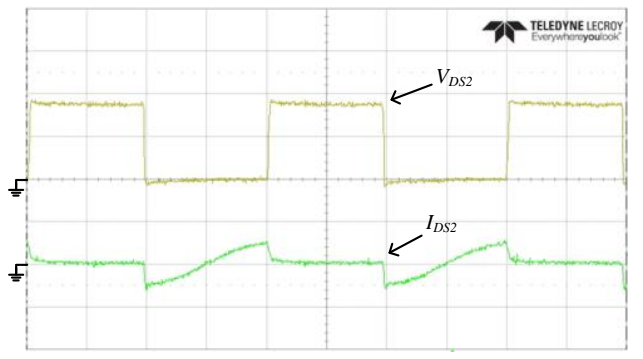

(VDC2: $100 \mathrm{~V} /$ div; IDS2: $1 \mathrm{~A} /$ div; $5 \mu \mathrm{s} /$ div)

(b)

Figure 19. Measured waveforms of (a) switch voltage $V_{D S 1}$ and current $I_{D S 1}$, and (b) switch voltage $V_{D S 2}$ and current $I_{D S 2}$ and current $I_{D S 2}$ under $30 \%$ of full load condition and the input voltage of $90 \mathrm{~V}$.

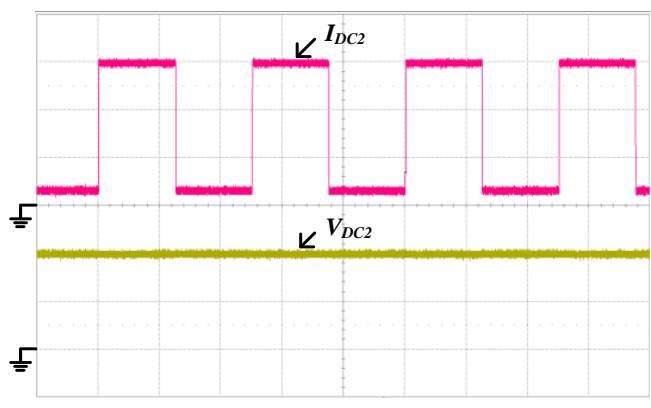

(VDC2: $25 \mathrm{~V} /$ div; IDC2: $2 \mathrm{~A} /$ div; time: $200 \mathrm{~ms} /$ div)

Figure 20. Measured output voltage $V_{D C 2}$ and current $I_{D C 2}$ waveforms of step-load changes between $10 \%$ and $100 \%$ of full load condition with duty ratio of $50 \%$ and repetitive period of $1 \mathrm{~s}$. 


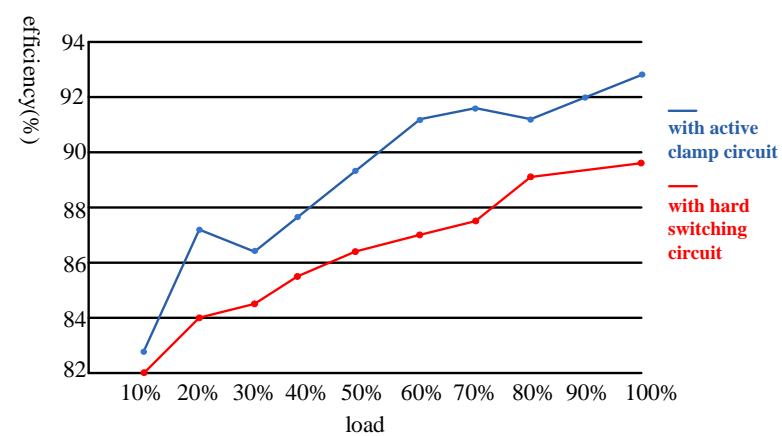

Figure 21. Measured efficiency of the proposed bridgeless flyback converter from light load to heavy load under $90 \mathrm{~V}$.

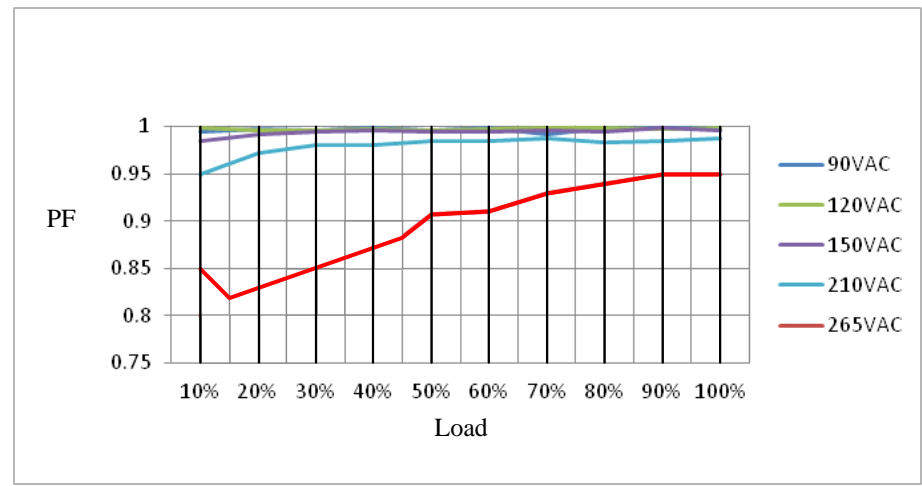

Figure 22. Plot of power factor of the proposed PFC from light load to heavy load under different input voltages.

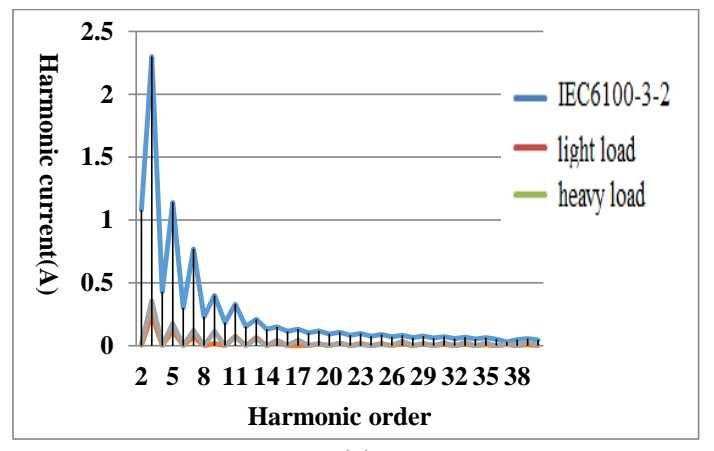

(a)

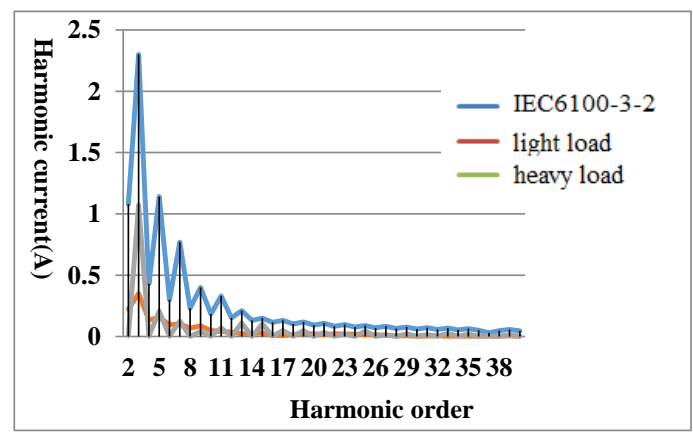

(b)

Figure 23. Plots of harmonic current at light load and heavy load (a) under input voltage of $90 \mathrm{~V}$, and (b) under input voltage of $265 \mathrm{~V}$.

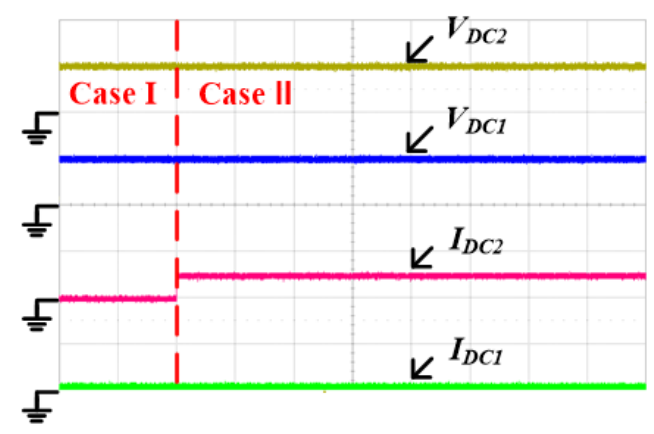

(VDC1: $50 \mathrm{~V} /$ div; $V_{D C 2}: 50 \mathrm{~V} /$ div; IDC1: $5 \mathrm{~A} /$ div; IDC2: $2.5 \mathrm{~A} /$ div; time: $200 \mathrm{~ms} / \mathrm{div}$ )

Figure 24. Operational state charges of the proposed power system from case I to case II under $P_{L}=125 \mathrm{~W}$. 


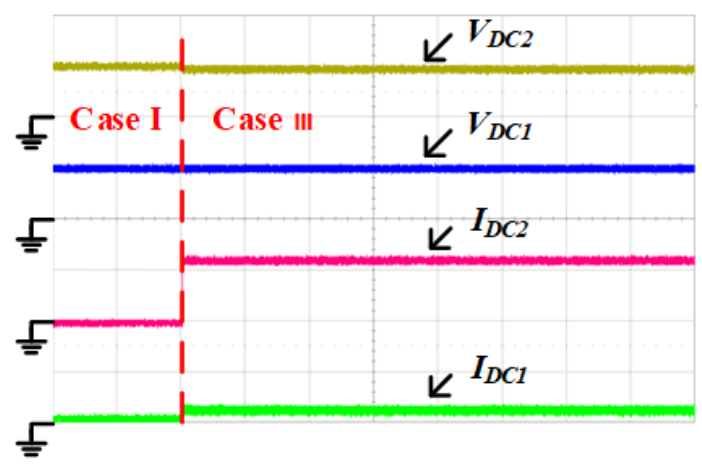

(VDC1: $50 \mathrm{~V} /$ div; $V_{D C 2}: 50 \mathrm{~V} / \mathrm{div}$; IDC1: $5 \mathrm{~A} / \mathrm{div} ; I_{D C 2}: 2.5 \mathrm{~A} / \mathrm{div}$; time: $200 \mathrm{~ms} / \mathrm{div}$ )

Figure 25. Operational state charges of the proposed power system from case I to case VI under $P_{L}=325 \mathrm{~W}$.

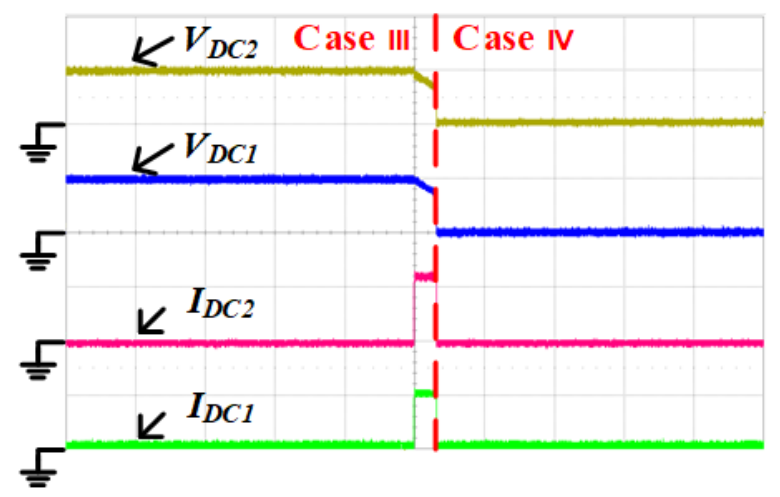

(VDC1: $50 \mathrm{~V} /$ div; $V_{D C 2}: 50 \mathrm{~V} /$ div; $I_{D C 1}: 5 \mathrm{~A} /$ div; $I_{D C 2}: 2.5 \mathrm{~A} /$ div; time: $200 \mathrm{~ms} /$ div)

Figure 26. Operational state charges of the proposed power system from case III to case IV under $P_{L}=450 \mathrm{~W}$.

\section{Conclusions}

This paper proposes a power system for DC load applications. The proposed power system adopts the DC/DC converter with battery source and the proposed PFC to supply power for DC loads of $48 \mathrm{~V}$ power system. The proposed PFC uses a bridgeless flyback converter to achieve a high PF. In this paper, operational principle and design of the proposed one have been described in detail. According to the experimental results, switches $M_{1}$ and $M_{2}$ of the proposed PFC can be operated with ZVS at turn-on transition. Furthermore, the proposed one can also achieve a lower harmonic current, a higher conversion efficiency and a higher PF. Its harmonic current from light load to heavy load under different input voltage levels can meet the requirements of IEC6100-3-2 class A. Therefore, the proposed bridgeless flyback converter has been implemented to apply to the utility line system as a power factor corrector. In addition, the proposed power system for DC loads of $48 \mathrm{~V}$ power system also has been implemented to verify its feasibility. It is suitable for a DC distribution of $48 \mathrm{~V}$ power system application.

Author Contributions: S.-Y.T. conceptualized the study, wrote the original draft and acquired funding; P.-J.H. and D.-H.W. did experiments and analyzed data.

Funding: The authors gratefully acknowledge the financial support (MOST 105-2221-E-182-046-MY3) of the Ministry of Science and Technology, Taiwan, R.O.C.

Conflicts of Interest: The authors declare no conflict of interest. 


\section{References}

1. Prabhala, V.A.K.; Baddipadiga, B.P.; Ferdowsi, M. DC Distribution Systems-An Overview. In Proceedings of the International Conference on Renewable Energy Research and Applications, Milwaukee, WI, USA, 19-22 October 2014; pp. 307-312.

2. Choi, H.; Balogh, L. A Cross-Coupled Master-Slave Interleaving Method for Boundary Conduction Mode (BCM) PFC Converters. IEEE Trans. Power Electron. 2012, 27, 4202-4211. [CrossRef]

3. Bist, V.; Singh, B. An Adjustable-Speed PFC Bridgeless Buck-Boost Converter-Fed BLDC Motor Drive. IEEE Trans. Ind. Electron. 2014, 61, 2665-2677. [CrossRef]

4. Roh, Y.-S.; Moon, Y.-J.; Park, J.; Yoo, C. A Two-Phase Interleaved Power Factor Correction Boost Converter with a Variation-Tolerant Phase Shifting Technique. IEEE Trans. Power Electron. 2014, 29, 1032-1040.

5. Zhang, F.; Xu, J. A Novel PCCM Boost PFC Converter with Fast Dynamic Response. IEEE Trans. Power Electron. 2011, 58, 4207-4216. [CrossRef]

6. Jang, Y.; Jovanovic, M.M. Interleaved Boost Converter with Intrinsic Voltage-doubler Characteristic for Universal-line PFC Front End. IEEE Trans. Power Electron. 2007, 22, 1394-1401. [CrossRef]

7. Xie, X.; Wang, J.; Zhao, C.; Lu, Q.; Liu, S. A Novel Output Current Estimation and Regulation Circuit for Primary Side Controlled High Power Factor Single-stage Flyback LED Driver. IEEE Trans. Power Electron. 2012, 27, 4602-4612. [CrossRef]

8. Baek, J.-I.; Kim, J.-K.; Lee, J.-B.; Youn, H.-S.; Moon, G.-W. A Boost PFC Stage Utilized as Half-Bridge Converter for High-Efficiency DC-DC Stage in Power Supply Unit. IEEE Trans. Power Electron. 2017, 32, 7449-7457. [CrossRef]

9. Mallik, A.; Khaligh, A. Control of a Three-Phase Boost PFC Converter Using a Single DC-Link Voltage Sensor. IEEE Trans. Power Electron. 2017, 32, 6481-6492. [CrossRef]

10. Reddy, U.R.; Narasimharaju, B.L. Single-stage electrolytic capacitor less non-inverting buck-boost PFC based AC-DC ripple free LED driver. IET Power Electron. 2017, 10, 38-46. [CrossRef]

11. Alam, M.; Eberle, W.; Gautam, D.S.; Botting, C. A Soft-Switching Bridgeless AC-DC Power Factor Correction Converter. IEEE Trans. Power Electron. 2017, 32, 7716-7726. [CrossRef]

12. Alam, M.; Eberle, W.; Gautam, D.S.; Botting, C.; Dohmeier, N.; Musavi, F. A Hybrid Resonant Pulse-Width Modulation Bridgeless AC-DC Power Factor Correction Converter. IEEE Trans. Ind. Appl. 2017, 53, 1406-1415. [CrossRef]

13. Lee, S.-W.; Do, H.-L. Single-Stage Bridgeless AC-DC PFC Converter Using a Lossless Passive Snubber and Valley Switching. IEEE Trans. Ind. Electron. 2016, 63, 6055-6063. [CrossRef]

14. Wu, X.; Wang, Z.; Zhang, J. Design Considerations for Dual-output Quasi-resonant Flyback LED Driver with Current-sharing Transformer. IEEE Trans. Power Electron. 2013, 28, 4820-4830. [CrossRef]

15. Zengin, S.; Deveci, F.; Boztepe, M. Decoupling Capacitor Selection in DCM Flyback PV Microinverters Considering Harmonic Distortion. IEEE Trans. Power Electron. 2013, 28, 816-825. [CrossRef]

16. Hsieh, Y.-C.; Chen, M.-R.; Cheng, H.-L. An Interleaved Flyback Converter Featured with Zero-voltage Transition. IEEE Trans. Power Electron. 2011, 26, 79-84. [CrossRef]

17. Lo, Y.-K.; Lin, J.-Y. Active-clamping ZVS Flyback Converter Employing Two Transformers. IEEE Trans. Power Electron. 2007, 22, 2416-2423. [CrossRef]

18. Baek, J.; Shin, J.; Jang, P.; Cho, B. A Critical Conduction Mode Bridgeless Flyback Converter. In Proceedings of the International Conference on Power Electronics, Jeju, Korea, 30 May-3 June 2011; pp. 487-492.

19. Chen, X.; Jiang, T.; Huang, X.; Zhang, J. A High Efficiency Bridgeless Flyback PFC Converter for Adapter Application. In Proceedings of the IEEE Applied Power Electronics Conference and Exposition, Long Beach, CA, USA, 17-21 March 2013; pp. 1013-1017.

20. Chang, H.-H.; Tseng, S.-Y.; Huang, J.G. Interleaving Boost Converters with a Single-Capacitor Turn-Off Snubber. In Proceedings of the IEEE Power Electronic Specialists Conference, Jeju, Korea, 18-22 June 2006; pp. 1-7.

(C) 2018 by the authors. Licensee MDPI, Basel, Switzerland. This article is an open access article distributed under the terms and conditions of the Creative Commons Attribution (CC BY) license (http:/ / creativecommons.org/licenses/by/4.0/). 